Check for updates

Cite this: RSC Adv., 2019, 9, 31747

\title{
Co-regulation of the copper vacancy concentration and point defects leading to the enhanced thermoelectric performance of $\mathrm{Cu}_{3} \mathrm{In}_{5} \mathrm{Te}_{9}$-based chalcogenides $\uparrow$
}

\author{
Min Li, ab Yong Luo, (DD *b Xiaojuan Hu, ${ }^{c}$ Zhongkang Han, ${ }^{* c}$ Xianglian Liu ${ }^{a}$ \\ and Jiaolin Cui $(\mathbb{D}$ *a
}

Copper vacancy concentration $\left(V_{c}\right)$ in ternary $\mathrm{Cu}-\mathrm{In}-\mathrm{Te}$ chalcogenides is an important factor to engineer carrier concentration $\left(n_{H}\right)$ and thermoelectric performance. However, it is not sufficient to regulate the phonon scattering in the $\mathrm{Cu}_{3} \mathrm{In}_{5} T e_{9}$-based chalcogenides. In this work we manipulate the $V_{c}$ value and point defects simultaneously through addition of $\mathrm{Cu}$ along with Ga substitution for $\mathrm{In}$ in $\mathrm{Cu}_{3} \mathrm{In}_{5} \mathrm{Te}_{9}$, and thereby increase the carrier concentration and reduce the lattice thermal conductivity. This strategy finally enables us to achieve $\sim 60 \%$ enhancement of the TE figure of merit $(Z T)$ at $V_{c}=0.078$ compared with the pristine $\mathrm{Cu}_{3} \ln _{5} \mathrm{Te}_{9}$. It is also used as guidance to achieve the high TE performance of the ternary chalcogenides.

Received 21st August 2019

Accepted 1st October 2019

DOI: $10.1039 / c 9 r a 06565 b$

rsc.li/rsc-advances

derivatives, such as $\mathrm{Cu}_{3} \mathrm{In}_{5} \mathrm{Te}_{9},{ }^{8-10} \mathrm{Cu}_{2.5} \mathrm{In}_{4.5} \mathrm{Te}_{8},{ }^{11} \mathrm{Cu}_{1.15} \mathrm{In}_{2.29^{-}}$ $\mathrm{Te}_{4},{ }^{12}$ and $\mathrm{Cu}_{3.52} \mathrm{In}_{4.16} \mathrm{Te}_{8}$ (ref. 13) with similar compositions.

\section{Introduction}

Thermoelectric (TE) materials have received much attention, as they can be effectively used in the fabrication of cooling and power generation systems. However, the conversion efficiency between heat and electricity is low, mainly due to the low performance of materials, which is governed by the dimensionless figure of merit, $Z T=a^{2} \sigma T / \kappa$. Here $a, \sigma, T, \kappa$ are the Seebeck coefficient, electrical conductivity, absolute temperature and total thermal conductivity consisting largely of electronic $\left(\kappa_{\mathrm{e}}\right)$ and lattice $\left(\kappa_{\mathrm{L}}\right)$ components respectively. Since the three parameters $a, \sigma$, and $\kappa_{\mathrm{e}}$ are strongly dependent on the carrier concentration $(n)$, it leaves $\kappa_{\mathrm{L}}$ the sole parameter that could be relatively independently tunable.

Classified as a Pb-free chalcogenide, ternary $\mathrm{Cu}-\mathrm{In}-\mathrm{Te}$ compounds have been widely studied as promising midtemperature thermoelectric candidates, in a sense that they have unique crystal and band structures. ${ }^{1-3}$ Among those the cation vacancy plays a vital role in determining both the carrier concentration and phonon transport. ${ }^{4-7}$ However, some controversies exist about the indexing and space group assignation on the crystal structure of the ternary $\mathrm{Cu}-\mathrm{In}-\mathrm{Te}$

${ }^{a}$ School of Materials and Chemical Engineering, Ningbo University of Technology, Ningbo 315016, China.E-mail: cuijiaolin@163.com

${ }^{b}$ Materials Science and Engineering College, China University of Mining and Technology, Xuzhou 221116, China.E-mail: sulyflying@cumt.edu.cn

${ }^{c}$ Theory Department, Fritz Haber Institute of the Max-Planck-Society, Faradayweg 4-6, D-14195 Berlin, Germany.E-mail: han@fhi-berlin.mpg.de

$\dagger$ Electronic supplementary information (ESI) available. See DOI: 10.1039/c9ra06565b
Therefore, tiny changes of the fabrication technology or compositions may lead to the different structure assignation. That is why we have observed several space groups for the identical Cu-In-Te compounds. Therefore, an accurate control of the composition and/or fabrication technology is strongly necessary. In addition to that, in ternary $\mathrm{Cu}_{3} \mathrm{In}_{5} \mathrm{Te}_{9}$ with a energy gap of $0.95 \mathrm{eV}$ (ref. 14) there is one ninth of cation site that is unoccupied in a unit cell, hence it can be expressed the general formula $\mathrm{Cu}_{3} \mathrm{In}_{5} \square \mathrm{Te}_{9}$, where the $\square$ represents the cation vacancy in the $2 a$ site, determined by Delgado etc. ${ }^{8}$ This cation vacancy enables the carrier concentration $(n)$ of $6.0 \times$ $10^{18} \mathrm{~cm}^{-3}$ to be obtained at room temperature (RT), ${ }^{9}$ close to the optimal one $\left(10^{19}-10^{21} \mathrm{~cm}^{-3}\right)$ required in TE materials. ${ }^{15}$ Hence it is anticipated that the ternary $\mathrm{Cu}_{3} \mathrm{In}_{5} \mathrm{Te}_{9}$ would be a potential TE candidate, even though many $\mathrm{Cu}$-In-Te ternary compounds have already presented their superior TE performance with the $Z T$ value of 1.61 for CuInTe ${ }_{2}-\mathrm{In}_{2} \mathrm{O}_{3},{ }^{1} 1.52$ for CuInTe ${ }_{2}-\mathrm{ZnS}^{16}$ and 1.65 for $\mathrm{Cu}_{3.52} \mathrm{In}_{4.16} \mathrm{Te}_{8}-\mathrm{Cu}_{2} \mathrm{Te}^{13}$

However, the cation vacancy has a dual effect on the transport properties. ${ }^{6,17,18}$ On one hand, the presence of the cation vacancy would unpin the Fermi level ${ }^{19}$ and affect the $p$ $d$ hybridization, ${ }^{20}$ thus having a potential to modify the bonding states of the constituent elements ${ }^{21}$ and tune the carrier concentration. ${ }^{22}$ In addition to that, it also introduces the mass fluctuation and enhances the phonon scattering on point defects. ${ }^{\mathbf{4}, 6,18,23}$ On the other hand, however, it is argued that too high cation vacancy concentration in p-type semiconductors may lead to a high hole density and low mobility resulting in 
fewer compensating electrons (deep donors). ${ }^{\mathbf{1 8 , 2 4 , 2 5}}$ Accordingly, the high Seebeck coefficient may be neutralized. ${ }^{26,27}$

Inspired by the above studies, it is necessary to manipulate the cation vacancy concentration and at the same time introduce the extra point defects in ternary chalcogenides. Therefore, we prepare a group of $\mathrm{Cu}_{3+x} \mathrm{In}_{5-x} \mathrm{Ga}_{x} \mathrm{Te}_{9}(x=0-0.4)$ chalcogenides in this work by using Ga substitution for In, aiming to introduce extra point defects $\left(\mathrm{Ga}_{\mathrm{In}}\right)$ to scatter phonons $^{25,28}$ and regulate the bandgap. ${ }^{29}$ The extra $\mathrm{Cu}$ in this compound is used to control the hole density ${ }^{5,30}$ and sustain a high Seebeck coefficient. The experimental results indicate that such a consideration brings a significant improvement in electrical conductivity and a reduction in lattice part $\kappa_{\mathrm{L}}$ simultaneously, which improves the TE performance effectively.

\section{Experimental}

\subsection{Sample preparation}

The materials $\mathrm{Cu}_{3+x} \mathrm{In}_{5-x} \mathrm{Ga}_{x} \mathrm{Te}_{9}(x=0,0.05,0.1,0.2,0.3,0.4)$ were synthesized by melting four elements ( $\mathrm{Cu}, \mathrm{In}, \mathrm{Ga}$ and $\mathrm{Te}$ ) (with the purity $>99.999 \%$, Emei Semicon. Mater. Co., Ltd. Sichuan, CN) in silica vacuum tubes at $1173 \mathrm{~K}$ for $24 \mathrm{~h}$, and then annealed at $800 \mathrm{~K}$ for $72 \mathrm{~h}$ followed by cooling in furnace to the room temperature (RT).

After cooling down to the room temperature (RT), the ingots were ball milled for $5 \mathrm{~h}$ at a rotation rate of $350 \mathrm{rpm}$ for $5 \mathrm{~h}$ in stainless steel bowls that contained benzinum. The dried powders were then rapidly sintered using spark plasma sintering apparatus (SPS-1030) at a peak temperature of $\sim 900 \mathrm{~K}$ and a pressure of $50 \mathrm{MPa}$. The densities $(d)$ of the polished bulks, which have more than $95 \%$ theoretical density, were measured using Archimedes' method.

The bulk samples with sizes of about $2.5 \times 3 \times 12 \mathrm{~mm}^{3}$ and $2 \times 2 \times 7 \mathrm{~mm}^{3}$ were prepared for electrical property and Hall coefficient measurements respectively, and those of $\phi 10 \times 1.5$ $\mathrm{mm}^{2}$ for thermal diffusivity measurement.

In terms of the above compositions, the copper vacancy concentration $V_{\mathrm{c}}$, which decreases as $x$ value increases, is 0.11 , $0.106,0.10,0.089,0.078,0.067$ respectively for the corresponding $x$ values, estimated by using the equation $V_{\mathrm{c}}=(1-x) / 9$.

\subsection{Physical property measurements}

The Seebeck coefficients and electrical conductivities were evaluated by using ZEM-3 (ULVAC-RIKO, Japan) under a helium atmosphere at a temperature ranging from $\sim$ RT to $\sim 830 \mathrm{~K}$ with an uncertainty of $<5.0 \%$ for each. The thermal diffusivities were measured using TC-1200RH (ULVAC-RIKO, Japan) with an uncertainty of $<10.0 \%$. The Dulong-Petit rule is used to estimate the heat capacities $\left(C_{\mathrm{p}}\right)$ above RT. The lattice thermal conductivity $\left(\kappa_{\mathrm{L}}\right)$ was the total $\kappa$ minus the electronic contribution $\left(\kappa_{\mathrm{e}}\right)$. Here $\kappa_{\mathrm{e}}$ is expressed by the Wiedemann-Franz $(\mathrm{W}-\mathrm{F})$ relation, $\kappa_{\mathrm{e}}=L_{0} \sigma T$, where $L_{0}$ is the Lorenz number, estimated using the formula $L_{0}=1.5+\exp (-|\alpha| / 116)^{31}$ (where $L_{0}$ is in $10 \times$ $10^{-8} \mathrm{~W} \Omega \mathrm{K}^{-2}$ and $|\alpha|$ in $\mu \mathrm{V} \mathrm{K} \mathrm{K}^{-1}$ ). The total uncertainty of the TE figure of merits (ZTs) is about $20 \%$.
Hall coefficients $\left(R_{\mathrm{H}}\right)$ were measured by using a four-probe configuration in a system (PPMS, Model-9) with a magnetic field up to $\pm 5 \mathrm{~T}$. The Hall mobility $(\mu)$ and carrier concentration $\left(n_{\mathrm{H}}\right)$ were calculated according to the relations $\mu=\left|R_{\mathrm{H}}\right| \sigma$ and $n_{\mathrm{H}}$ $=1 /\left(e R_{\mathrm{H}}\right)$ respectively, where $e$ is the electron charge.

\subsection{Structural, compositions and thermal analyses}

The chemical compositions were determined using an electron probe micro-analyzer (EPMA) (S-4800, Hitachi, Japan) with an accuracy of $>97 \%$.

The structural analysis of the powders was made by powder $\mathrm{X}$-ray diffractometer (D8 Advance) operating at $50 \mathrm{kV}$ and $40 \mathrm{~mA}$ at $\mathrm{Cu} \mathrm{K} \alpha$ radiation $(\lambda=0.15406 \mathrm{~nm})$ in the $2 \theta$ range from $10^{\circ}$ to $110^{\circ}$ with a step size of $0.02^{\circ}$, and a X'Pert Pro, PANalytical code was used to do the Rietveld refinement of the XRD patterns with a step size of $0.01^{\circ}$ using the same operating voltage and current. The lattice constants $a$ and $c$ were directly obtained from the refinement of the XRD patterns using Jade software (Highscore (plus) Software version 4.0 by PANalytical B.V; Almelo, The Netherlands) ${ }^{32}$ with an error less than $10 \%$.

Differential Scanning calorimeter (DSC) and thermogravimetry (TG) were conducted in a Netzch STA 449 F3 Jupiter equipped with a TASC414/4 controller. The instrument was calibrated from a standard list. The sample of the powder $(x=$ 0 ) was loaded into an open alumina crucible. The measurement was performed after the samples were heated up to $\sim 850 \mathrm{~K}$ with a heating rate of $5 \mathrm{~K} \mathrm{~min}^{-1}$ in Ar atmosphere.

\subsection{Methodology}

First-principles calculations are carried out with FHIaims, ${ }^{33,34}$ an all-electron, full-potential electronic-structure code under the framework of density-functional theory (DFT). ${ }^{35}$ FHI-aims uses numeric atom-centered basis sets, where numerical settings are so chosen for the present study that a convergence in energy differences better than $10^{-3} \mathrm{eV}$ per atom is achieved. Generalized gradient approximation (GGA) is used for electronic exchange and correlation as Perdew-Burke-Ernzerhof (PBE). ${ }^{36}$ We have calculated the electronic structure with more advanced Heyd-ScuseriaErnzerhof hybrid functional (HSE06), ${ }^{37}$ which takes into account fraction of exact exchange.

\section{Results and discussions}

\subsection{Composition analysis and XRD patterns}

The scanning electron microscopy (SEM) images of freshly fractured surface and the energy-dispersive X-ray spectroscopy (EDS) of the sample at $x=0.3$ are shown in Fig. S1a and $\mathrm{b} . \dagger$ The analyzed average molars in $\left(\mathrm{Cu}_{3+x} \mathrm{In}_{5-x} \mathrm{Ga}_{x} \mathrm{Te}_{9}\right)(x=0,0.1,0.3)$ (taken from three different areas) are shown in Table S1.† It is observed that the sums of the molars of three to four elements are not exactly equal to the nominal ones with a slight deficiency in $\mathrm{Cu}$ and excess in Te, likely due to the composition segregation in the different areas. However, the cation vacancy still exists because the total numbers of cations are less than 
those of anion Te. Besides, the analyzed composition in each sample is roughly in accordance with the starting materials.

The refinements of the powder X-ray diffraction (XRD) patterns of the four samples $(x=0,0.1,0.2,0.4)$ are shown in Fig. S2. $\uparrow$ The refined parameters $\left(R_{\mathrm{B}}, R_{\mathrm{p}}, R_{\mathrm{wp}}, S\right.$ etc. $)$ are listed in Tables S2-S5. $\dagger$ The powder diffraction patterns (Fig. 1a) show that the materials exhibit a single $\mathrm{Cu}_{3} \mathrm{In}_{5} \mathrm{Te}_{9}$ phase, because the diffraction peaks can be accurately indexed to the existing diffraction data in ref. 9 (s.g.: $P 4 \mathrm{~mm}$ ). Compared to the data in PDF:51-0804 (s.g.: P4(75)), the peak corresponding to the crystal plane (112) or (222) with the $d$-spacing of $3.088 \AA$ reported in ref. 9 is visible in the refinement patterns (see Fig. S2†). This indicates that the element $\mathrm{Ga}$ is totally incorporated into the lattice structure. Besides, the lattice constants $(a, b, c)$ decrease linearly with the increase of the $x$ value following the Vegard's law (see Fig. $1 \mathrm{~b}$ and Tables $\mathrm{S} 2-\mathrm{S} 5 \dagger$ ), due to the smaller radius of Ga than that of In, indicating the shrinkage of the crystal structure.

\subsection{Microstructure analyses}

In order to further confirm the synthesis of titled alloys, the microstructures of the samples at $x=0\left(V_{\mathrm{c}}=0.11\right)$ and $0.3\left(V_{\mathrm{c}}=\right.$ 0.078) have been examined by using high-resolution TEM (HRTEM). Fig. S3a $\uparrow$ is the TEM image of the powder sample $(x=$ 0 ), and Fig. S3b $\dagger$ is the corresponding HRTEM image. Fig. S3c $\dagger$ is the corresponding selected area electron diffraction (SAED) pattern, and Fig. S3d $\dagger$ showing zoomed view of Fig. S3b, $\dagger$ in which the $d$ spacing between (002) crystal planes is about $0.364 \mathrm{~nm}$. This value is a little larger than $0.357 \mathrm{~nm}$ indicated in PDF51-0804. Fig. S4a and $\mathrm{b} \dagger$ are the TEM and HRTEM images for the sample at $x=0.3$. Fig. S4c $\dagger$ is the corresponding SAED pattern, and Fig. S4d $\dagger$ is an enlarged image. The $d$ spacing between (002) crystal planes is $\sim 0.33 \mathrm{~nm}$, about $0.027 \mathrm{~nm}$ less. The decreasing tendency in $d$ spacing is caused by the smaller atomic Ga than In, in a good agreement with the analyzed XRD data (Fig. 1b).

\subsection{Band structures}

In order to have a better understanding of the changes of the transport properties upon Ga substitution in $\mathrm{Cu}_{3} \mathrm{In}_{5} \mathrm{Te}_{9}$, we calculate the band structures of $\mathrm{Cu}_{10} \mathrm{In}_{17} \mathrm{Te}_{32}$ (Fig. S5a $\dagger$ ) and $\mathrm{Cu}_{11} \mathrm{In}_{16} \mathrm{GaTe}_{32}$ with an extra $\mathrm{Cu}$ addition and $\mathrm{Ga}$ residing at the In site (Fig. S5b $\mathrm{b}^{\dagger}$ ). It is observed the conduction band
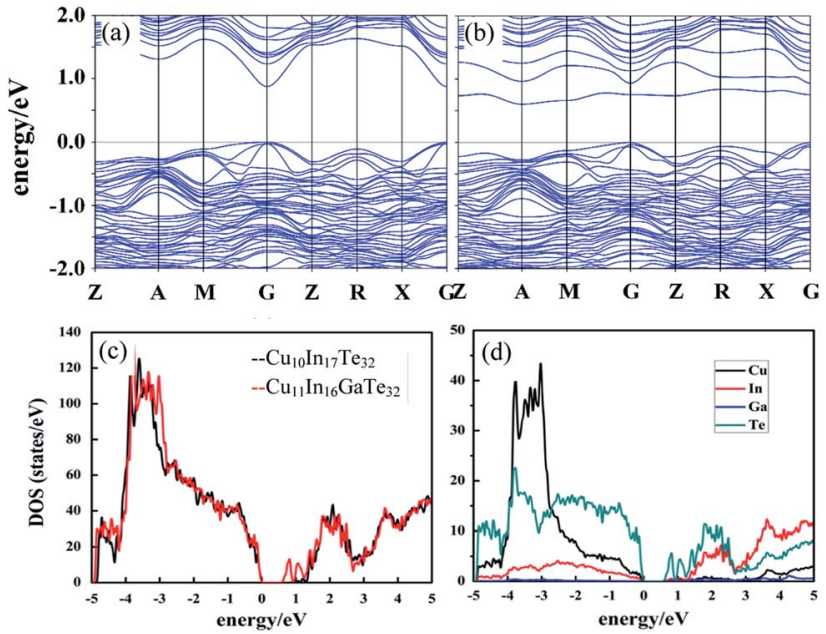

Fig. 2 Electronic band structures of (a) $\mathrm{Cu}_{10} \mathrm{In}_{17} \mathrm{Te}_{32}$ and (b) $\mathrm{Cu}_{11}$ $\mathrm{In}_{16} \mathrm{GaTe}_{32}$; (c) density of the states (DOS) for $\mathrm{Cu}_{10} \mathrm{In}_{17} \mathrm{Te}_{32}$ and $\mathrm{Cu}_{11^{-}}$ $\ln _{16} \mathrm{GaTe}_{32}$; (d) projected densities of the states (PDOS) for $\mathrm{Cu}_{11} \mathrm{In}_{16} \mathrm{GaTe}_{32}$. The highest occupied state is set as the zero energy value. It was observed that the conduction bands move down upon substitution of Ga for In, which narrows the bandgap.

(CB) moves down upon an incorporation of Ga (Fig. 2a and b), while the valence band maximum (VBM) remains the same energy level (Fig. $2 \mathrm{~b}$ and $\mathrm{c}$ ), which narrows the bandgap $\left(E_{\mathrm{g}}\right)$ from $\sim 1.0 \mathrm{eV}$ to $0.7 \mathrm{eV}$. According to the Goldsmid estimation $E_{\mathrm{g}}=2 e|\alpha|_{\max } T_{\max },{ }^{38}$ the $E_{\mathrm{g}}$ value decreases from $0.64 \mathrm{eV}$ to $0.43 \mathrm{eV}$ as $x$ value increases from 0 to 0.3 . Here, the $|\alpha|_{\max }$ represents the highest Seebeck coefficients (see below), $T_{\max }$ temperature at which the highest Seebeck coefficients present, and $e$ electronic charge. Although the estimated $E_{\mathrm{g}}$ values are somewhat inaccurate, they are only a little lower than $n \kappa_{\mathrm{B}} T(n=6-10)$ (0.42-0.68 eV to $0.52-0.87 \mathrm{eV}$ ) for the best direct-gap TE materials. ${ }^{39}$ This implies that the Goldsmid's equation is still useful to estimate the bandgap, in terms of the Gibbs's suggestion. ${ }^{40}$ Besides, the incorporation of Ga flattens the conduction band (CB) and brings valence band (VB) at $\mathrm{Z}, \mathrm{R}$ and $\mathrm{G}$ points closer in energy (Fig. 2b), thus resulting in $\mathrm{CB}$ and $\mathrm{VB}$ convergences (Fig. 2a and b). Although the contribution of the orbital Ga in both the VBM and CBM seems to
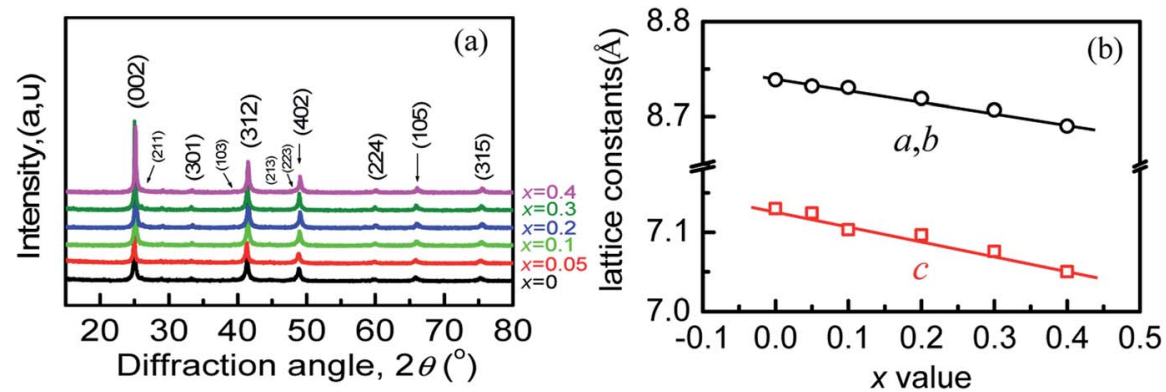

Fig. 1 (a) X-ray diffraction patterns of the $\mathrm{Cu}_{3+x} \mathrm{In}_{5-x} \mathrm{Ga}_{x} T e_{9}$ powders; (b) lattice constants $a, b$ and $c$ as a function of $x$ value, which follows the Vegard's law. 
be limited (Fig. 2d), it might play a significant role in promoting the down-movement of $\mathrm{CB}$, in addition to the flattening of CB. Such changes in band structure would evidently enhance the carrier concentration.

\subsection{Transport and TE performance}

To evidence the above assumption, we have measured the Hall coefficients at RT and then obtained the Hall carrier concentrations $\left(n_{\mathrm{H}}\right)$ and mobility. The measurements show that the $n_{\mathrm{H}}$ value increases from $1.96 \times 10^{18} \mathrm{~cm}^{-3}(x=0)$ to $\sim 1.0 \times 10^{19}$ $\mathrm{cm}^{-3}(x=0.3)$ before it starts to fall, albeit very slightly, to 9.44 $\times 10^{18} \mathrm{~cm}^{-3}(x=0.4)$, while the Hall mobility $(\mu)$ increases from $25.0 \mathrm{~cm}^{2} \mathrm{~V}^{-1} \mathrm{~s}^{-1}(x=0)$ to $33.9 \mathrm{~cm}^{2} \mathrm{~V}^{-1} \mathrm{~s}^{-1}(x=0.1)$, and then decreases to $13.2 \mathrm{~cm}^{2} \mathrm{~V}^{-1} \mathrm{~s}^{-1}$ at $x=0.4$, as shown in Fig. 3 . The general enhancement in $n_{\mathrm{H}}$ is due to the bandgap narrowing, while the reduction in mobility $\mu$ is mainly ascribed to the increased carrier scattering. As the $x$ value increases the copper vacancy $V_{c}$ decreases. This implies that the presence of the high copper vacancy is not beneficial to the carrier concentration.

The thermoelectric performance is presented in Fig. 4, where the Seebeck coefficients $(\alpha)$ are shown as a function of temperature in Fig. 4a. The positive $\alpha$ values indicate the p-type semiconductor behavior of the materials. With the $x\left(V_{\mathrm{c}}\right)$ value increasing (decreasing), the highest $\alpha$ value decreases from $315.9 \mu \mathrm{V} \mathrm{K}^{-1}\left(x=0, V_{\mathrm{c}}=0.11\right)$ to $268.2 \mu \mathrm{V} \mathrm{K}{ }^{-1}\left(x=0.3, V_{\mathrm{c}}=\right.$ 0.078 ), and so does the temperature at which the highest $\alpha$ value appears, guided by a gray arrow in Fig. 4a. This implies that the bandgap narrows as $x$ ( $\left.V_{\mathrm{c}}\right)$ value increases (decreases), which is in accordance with the first-principles calculation. However, the $\alpha$ values at $x=0.4\left(V_{\mathrm{c}}=0.067\right)$ are higher than those at $x=0.3$ $\left(V_{\mathrm{c}}=0.078\right)$, which might be the low carrier concentration at $x=$ $0.4\left(V_{\mathrm{c}}=0.067\right)$.

Besides, above $\sim 700 \mathrm{~K}$ the Seebeck coefficients of all the samples decrease rapidly with temperature increasing, and then keep a relatively stable value above $\sim 730 \mathrm{~K}$. Such a change is most likely to be related to the order-disorder transition near $700 \mathrm{~K}$ (Fig. S6 $\dagger$ ). ${ }^{41-43}$ The combined TGA/DSC analyses of the material from ambient temperature to $\sim 850 \mathrm{~K}$ reveal an exothermic effect around $700 \mathrm{~K}$, which confirms this issue. Unfortunately, this transition has not been reported in detail previously. ${ }^{\mathbf{1 4 , 4 4 , 4 5}}$ Besides, there is little or no indication of element Te evaporation below $\sim 740 \mathrm{~K}$ from the DSC curve. Only

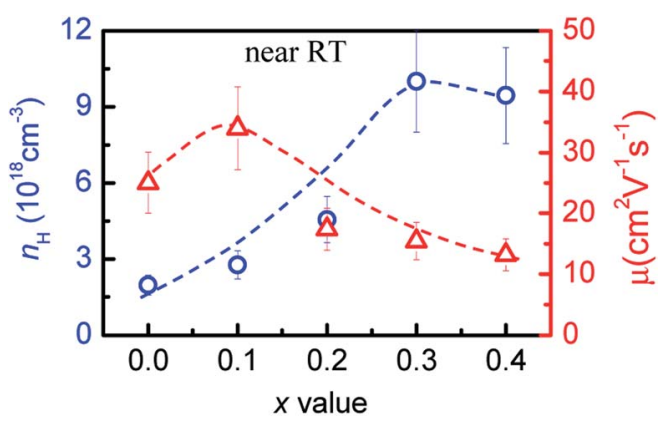

Fig. 3 Hall carrier concentration $\left(n_{H}\right)$ and mobility $(\mu)$ as a function of $x$ value in $\mathrm{Cu}_{3+x} \ln n_{5-x} \mathrm{Ga}_{x} \mathrm{Te}_{9}$. when the temperature rises to above $\sim 740 \mathrm{~K}$ does the weight loss of the sample occur. Therefore, the scattered data of the TE properties above $740 \mathrm{~K}$ might be ascribed to the deprivation of gravity.

Fig. $4 \mathrm{~b}$ is the temperature-dependent electrical conductivities $(\sigma)$, which increase with temperature until at $\sim 730 \mathrm{~K}$. Above $\sim 730 \mathrm{~K}$, the materials exhibit metallic-like behavior, as was observed in $\mathrm{AgGa}_{1-x} \mathrm{Te}_{2}$ system. ${ }^{46}$ Besides, it is noted that the electrical conductivity at $\sim 822 \mathrm{~K}$ increases from $5.7 \times 10^{3} \Omega^{-1}$ $\mathrm{m}^{-1}\left(x=0, V_{\mathrm{c}}=0.11\right)$ to $11.4 \times 10^{3} \Omega^{-1} \mathrm{~m}^{-1}\left(x=0.3, V_{\mathrm{c}}=0.078\right)$ before it starts to fall to the $8.7 \times 10^{3} \Omega^{-1} \mathrm{~m}^{-1}\left(x=0.4, V_{\mathrm{c}}=\right.$ 0.067 ), which corresponds to the variations in carrier concentration and mobility (Fig. 3). The lattice thermal conductivities $\left(\kappa_{\mathrm{L}}\right)$ are displayed as a function of temperature in Fig. $4 \mathrm{c}$, where the inset is the total $\kappa$. Roughly, the lattice parts $\left(\kappa_{\mathrm{L}}\right)$ bear resemblance to total $\kappa$, which suggests that the phonon transport plays a major role in heat carrying. With the $x\left(V_{\mathrm{c}}\right)$ value increasing (decreasing), the lattice part $\left(\kappa_{\mathrm{L}}\right)$ reduces generally. However, above $\sim 780 \mathrm{~K}$ the $\kappa_{\mathrm{L}}(\kappa)$ at $x=0.3\left(V_{\mathrm{c}}=0.078\right)$ reduce relatively rapidly, and at $\sim 822 \mathrm{~K}$ they reach the lowest values, $0.30 \mathrm{Wm}^{-1} \mathrm{~K}^{-1}$ and $0.52 \mathrm{Wm}^{-1} \mathrm{~K}^{-1}$. The rapid reduction in $\kappa_{\mathrm{L}}$ at high temperatures is likely attributed to the enhanced point defect scattering of phonons resulting from the combined effects of $\mathrm{Ga}_{\mathrm{In}}$ and copper vacancy. However, the high $\kappa_{\mathrm{L}}$ values $\left(x=0.4, V_{\mathrm{c}}=0.067\right)$ at high temperatures might be due to the fact that the weakened scattering of phonons at copper vacancies neutralizes to some extent the scattering on the defect $\mathrm{Ga}_{\text {In }}$. It is therefore concluded that a co-regulation of copper vacancy concentration $\left(V_{c}\right)$ and the extra point defects is essential to minimize the lattice component $\kappa_{\mathrm{L}}$.

Combined with the above transport properties, the highest $Z T$ value of $\sim 0.8$ is attained at $x=0.3\left(V_{\mathrm{c}}=0.078\right)$, as shown in Fig. 4 d. Although this $Z T$ value is not high compared with those of the state-of-the-art TE materials, such as PbTe- ${ }^{47} \mathrm{SnSe}^{48}$ $\mathrm{CuGa}(\mathrm{In}) \mathrm{Te}_{2}$-based TE compounds, ${ }^{1,49}$ it has $\sim 60 \%$ enhancement compared to the pristine $\mathrm{Cu}_{3} \mathrm{In}_{5} \mathrm{Te}_{9}\left(x=0, V_{\mathrm{c}}=0.11\right)$. This emphasizes the importance again of co-regulation of the copper vacancy concentration and point defects in $\mathrm{Cu}_{3} \mathrm{In}_{5} \mathrm{Te}_{9}$-based chalcogenides.

In order to further elucidate the highest TE performance of the material with $V_{\mathrm{c}}=0.078$, we, specifically, present the relationship between the copper vacancy concentration $\left(V_{\mathrm{c}}\right)$ and lattice thermal conductivity $\left(\kappa_{\mathrm{L}}\right)$. The result is shown in Fig. 5, where we have observed that the lattice parts $\left(\kappa_{\mathrm{L}}\right)$ at $\sim \mathrm{RT}, \sim 693$ $\mathrm{K}$ and $\sim 822 \mathrm{~K}$ tend to increase as the $V_{\mathrm{c}}$ value increases. The solid lines in Fig. 5 are indicated as a guidance for eye. Although the lattice parts $\left(\kappa_{\mathrm{L}}\right)$ in the present chalcogenides are related to the combined scatterings, that is, phonon scatterings at point defects of copper vacancy and $\mathrm{Ga}_{\mathrm{In}}$, the above dependences at least indicate that the cation vacancy concentration does not play a predominant role in scattering phonons. Only when the material has a proper $V_{\mathrm{c}}$ value $\left(V_{\mathrm{c}}=0.078\right)$ combined with an extra point defect $\mathrm{Ga}_{\mathrm{In}}$, are the electrical and thermal properties co-optimized. This finding does not support the common understanding that the presence of cation vacancy in ternary chalcogenides has a definitely positive effect on either the carrier concentration ${ }^{5}$ or phonon scattering. ${ }^{17,23}$ 

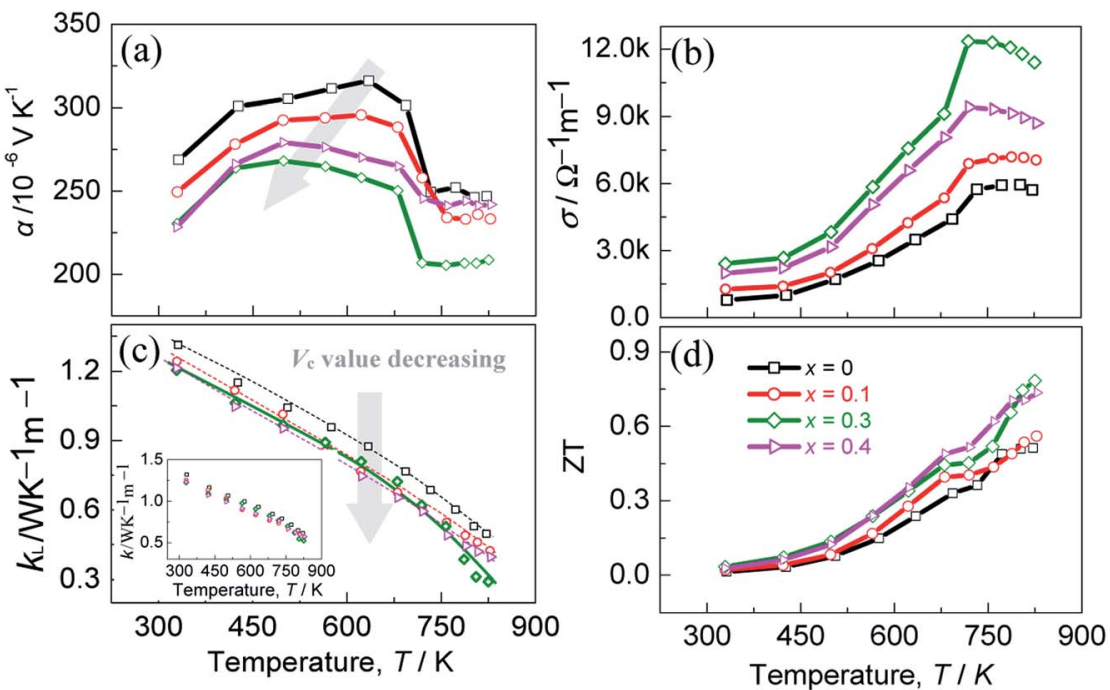

Fig. 4 Thermoelectric performance of the materials as a function of temperature for different $x$ values. (a) Seebeck coefficients $(\alpha)$ as a function of temperature; (b) electrical conductivity $(\sigma)$ as a function of temperature; (c) lattice thermal conductivity $\left(\kappa_{\mathrm{L}}\right)$ as a function of temperature, the inset is the total $\kappa ;(d)$ dimensionless figure of merit $(Z T)$ as a function of temperature.

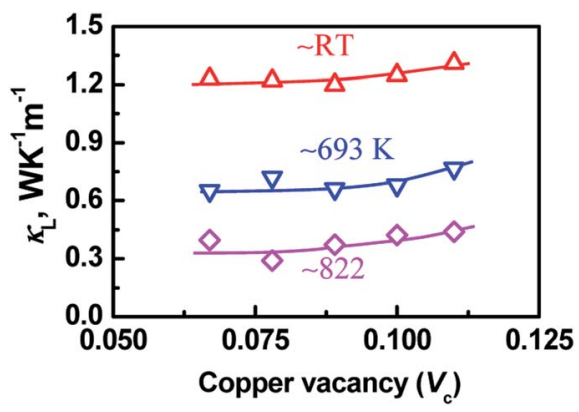

Fig. 5 Lattice thermal conductivities at $\sim \mathrm{RT}$, $\sim 693 \mathrm{~K}$ and $\sim 822 \mathrm{~K}$ as a function of copper vacancy concentration $\left(V_{c}\right)$.

\section{Conclusions}

In summary, the $\mathrm{Cu}_{3} \mathrm{In}_{5} \mathrm{Te}_{9}$-based chalcogenides with a substitution of $\mathrm{Ga}$ for In and an addition of extra $\mathrm{Cu}$ were prepared and their TE performance were investigated. The results reveal that the co-regulation of the copper vacancy concentration $\left(V_{\mathrm{c}}\right)$ and phonon scattering are vital to improve the TE performance. The optimal $V_{\mathrm{c}}$ is 0.078 in these compounds at which the highest TE figure of merit $Z T$ of $\sim 0.8$ is attained at $\sim 822 \mathrm{~K}$, which is $\sim 60 \%$ higher than that of pristine $\mathrm{Cu}_{3} \mathrm{In}_{5} \mathrm{Te}_{9}$. This indicates that the co-regulation of the copper vacancy and phonon scattering might be a good way to explore the high performance TE chalcogenides.

\section{Conflicts of interest}

There are no conflicts of interest to declare.

\section{Acknowledgements}

This work is supported by the National Natural Science Foundation of China (51671109, 51171084).

\section{Notes and references}

1 Y. Luo, J. Yang, Q. Jiang, W. Li, D. Zhang, Z. Zhou, Y. Cheng, Y. Ren and X. He, Adv. Energy Mater., 2016, 6, 1600007.

2 F. Fan, L. Wu and S. Yu, Energy Environ. Sci., 2014, 7, 190.

3 A. Kosuga, K. Umekage, M. Matsuzawa, Y. Sakamoto and I. Yamada, Inorg. Chem., 2014, 53, 6844.

4 J. Shen, X. Zhang, S. Lin, J. Li, Z. Chen, W. Li and Y. Pei, J. Mater. Chem. A, 2016, 4, 15464.

5 A. Yusufu, K. Kurosaki, A. Kosuga, T. Sugahara, Y. Ohishi, H. Muta and S. Yamanaka, Appl. Phys. Lett., 2011, 99, 061902.

6 Z. Xia, G. Wang, X. Zhou and W. Wen, Ceram. Int., 2017, 43, 16276.

7 R. Liu, Y. Qin, N. Cheng, J. Zhang, X. Shi, Y. Grin and L. Chen, Inorg. Chem. Front., 2016, 3, 1167.

8 G. E. Delgado, C. Rincón and G. Marroquín, Rev. Mex. Fis., 2019, 65, 360.

9 M. Parlak, Ç. Erçelebi, İ. Günal, H. Özkan, N. M. Gasanly and A. Çulfaz, Cryst. Res. Technol., 1997, 32, 395.

10 C. C. Rincón, S. M. Wasim, G. Marín, J. M. Delgado and J. Contreras, Appl. Phys. Lett., 2003, 83, 1328.

11 T. Ren, P. Ying, G. Cai, X. Li, Z. Han, L. Min and J. Cui, RSC Adv., 2018, 8, 27163.

12 M. Li, Y. Luo, G. Cai, X. Li, X. Li, Z. Han, X. Lin, D. Sarker and J. Cui, J. Mater. Chem. A, 2019, 7, 2360.

13 T. Ren, Z. Han, P. Ying, X. Li, X. Li, X. Lin, D. Sarker and J. Cui, ACS Appl. Mater. Interfaces, 2019, 11, 32192. 
14 E. Guedeza, L. Mogollónb, G. Marcanoa, S. M. Wasima, G. Sánchez Péreza and C. Rincón, Mater. Lett., 2017, 186, 155.

15 G. J. Snyder and E. S. Toberer, Nat. Mater., 2008, 7, 105.

16 Y. Luo, Q. Jiang, J. Yang, W. Li, D. Zhang, Z. Zhou, Y. Cheng, Y. Ren, X. He and X. Li, Nano Energy, 2017, 32, 80.

17 T. Plirdpring, K. Kurosaki, A. Kosuga, M. Ishimaru, A. Harnwunggmoung, T. Sugahara, Y. Ohishi, H. Muta and S. Yamanaka, Mater. Trans., 2012, 53, 1212.

18 K. Kurosaki and S. Yamanaka, Phys. Status Solidi A, 2013, 210, 82.

19 A. Klein and W. Jaegermann, Appl. Phys. Lett., 1999, 74, 2283.

20 S. M. Wasim, C. Rincón, G. Marín and J. M. Delgado, Appl. Phys. Lett., 2000, 77, 94.

21 Y. Fujii, K. Tanaka and A. Kosuga, Scr. Mater., 2019, 162, 272. 22 K. Wang, P. Qin, Z. Ge and J. Feng, Scr. Mater., 2018, 149, 88. 23 Z. Ye, J. Cho, M. M. Tessema, J. R. Salvador, R. A. Waldo, H. Wang and W. Cai, J. Solid State Chem., 2013, 201, 262.

24 S. Wei, S. B. Zhang and A. Zunger, Appl. Phys. Lett., 1998, 72, 3199.

25 Y. Qin, P. Qiu, R. Liu, Y. Li, F. Hao, T. Zhang, D. Ren, X. Shi and L. Chen, J. Mater. Chem. A, 2016, 4, 1277.

26 J. Cui, G. Cai and W. Ren, RSC Adv., 2018, 8, 21637.

27 J. Yang, S. Chen, Z. Du, X. Liu and J. Cui, Dalton Trans., 2014, 43, 15228.

28 W. D. Carr and D. T. Morelli, J. Alloys Compd., 2015, 630, 277.

29 R. Guevara, G. Marín, J. M. Delgado, S. M. Wasim, C. Rincón and G. Sánchez Pérez, J. Alloys Compd., 2005, 393, 100.

30 A. Kosuga, T. Plirdpring, R. Higashine, M. Matsuzawa, K. Kurosaki and S. Yamanaka, Appl. Phys. Lett., 2012, 100, 042108.

31 H. Kim, Z. M. Gibbs, Y. Tang, H. Wang and G. J. Snyder, APL Mater., 2015, 3, 041506.

32 T. Degen, M. Sadki, E. Bron, U. König and G. Nénert, Powder Diffr., 2014, 29, S13-S18.
33 V. Blum, R. Gehrke, F. Hanke, P. Havu, V. Havu, X. Ren, K. Reuter and M. Scheffler, Comput. Phys. Commun., 2009, 180, 2175.

34 P. Hohenberg and W. Kohn, Phys. Rev., 1964, 136, B864.

35 W. Kohn and L. J. Sham, Phys. Rev., 1965, 140, A1133.

36 J. P. Perdew, K. Burke and M. Ernzerhof, Phys. Rev. Lett., 1996, 77, 3865.

37 A. V. Krukau, O. A. Vydrov, A. F. Izmaylov and G. E. Scuseria, J. Chem. Phys., 2006, 125, 224106.

38 H. J. Goldsmid and J. W. Sharp, J. Electron. Mater., 1999, 28, 869.

39 J. O. Sofo and G. D. Mahan, Phys. Rev. B: Condens. Matter Mater. Phys., 1994, 49, 4565.

40 Z. M. Gibbs, H. Kim, H. Wang and G. J. Snyder, Appl. Phys. Lett., 2015, 106, 022112.

41 A. Zunger, Appl. Phys. Lett., 1987, 50, 164.

42 S. Schorr, G. Geandier and B. V. Korzun, Phys. Status Solidi C, 2006, 3, 2610.

43 C. Rincón, Solid State Commun., 1987, 64, 663.

44 H. Özkan, N. Gasanly, İ. Yilmaz, A. Çulfaz and V. Naglev, Turk. J. Phys., 1998, 22, 519.

45 N. M. Gasaanly, A. G. Guseinov, E. A. Aslanov and S. A. ELHamid, Phys. Status Solidi B, 1990, 158, K85.

46 X. Su, N. Zhao, S. Hao, C. C. Stoumpos, M. Liu, H. Chen, H. Xie, Q. Zhang, C. Wolverton, X. Tang and M. G. Kanatzidis, Adv. Funct. Mater., 2018, 29, 1806534.

47 J. Zhang, D. Wu, D. He, D. Feng, M. Yin, X. Qin and J. He, Adv. Mater., 2017, 29, 1703148.

48 L. Zhao, G. Tan, S. Hao, J. He, Y. Pei, H. Chi, H. Wang, S. Gong, H. Xu, V. P. Dravid, C. Uher, G. J. Snyder, C. Wolverton and M. G. Kanatzidis, Science, 2016, 351, 141.

49 T. Plirdpring, K. Kurosaki, A. Kosuga, T. Day, S. Firdosy, V. Ravi, G. J. Snyder, A. Arnwunggmoung, T. Sugahara, Y. Ohishi, H. Muta and S. Yamanaka, Adv. Mater., 2012, 24, 3622 . 